\title{
Citizens of the future: virtual reality as a visualization of possible narratives
}

\section{SIGRADI2018 TECHNOPOLITICAS \\ xxii congresso da sociedade iberoamericana de gráfica digital 22th conference of the iberoamerican society of digital graphics 07|08|09|novembro|2018 iau usp | são carlos | sp br}

\author{
Mariana Maia Nantes Coelho \\ Universidade Federal do Mato Grosso do Sul | Brazil | marianamaianc@gmail.com \\ Gilfranco Alves \\ Universidade Federal do Mato Grosso do Sul | Brazil | gilfrancoalves@gmail.com
}

\begin{abstract}
This article develops and analyses actions carried out with 5 to 13 years old children, realized in Campo Grande (Brazil) and Duclair (France). They offer the possibility to define the importance of physical spaces through narrated tales and children's interpretation by the mean of digital modeling and so virtual reality. The study's aim is to develop future citizens' sensitivity and critical eve regarding spaces, but also providing them tools so they can have a better perception over cities.
\end{abstract}

Keywords: Virtual reality; Tales; Childhood; Citizenship; Education.

\section{INTRODUÇÃO}

O presente artigo foi desenvolvido como parte do projeto de pesquisa "Cultura Digital e Processos Digitais de Projeto", junto ao grupo Algo+Ritmo da UFMS e visa dialogar com o tema do congresso, no sentido de discutir e analisar práticas de ensino em contextos digitais, a partir de experiências realizadas com crianças entre 5 e 13 anos, no Brasil (Campo Grande, Mato Grosso do Sul) e na França (Duclair, Normandia), visualizando o potencial educativo de se trabalhar com mediação digital.

A lembrança, a projeção de uma vida futura, a fuga por uma imersão em um livro, em tudo isso há algo em comum: o espaço a e sua subjetividade. Bachelard (2000) analisa essa relação afetiva das memórias e a construção poética dos espaços ao dizer que em sua consciência, o homem acessa os lugares de sua memória: "Só eu, nas minhas lembranças de outro século, posso abrir o armário que guarda ainda, só para mim, o cheiro único, o cheiro das uvas que secam sobre a sebe". (Bachelard, 2000 p. 206)

Nesse contexto, o autor afirma que é possível revisitar os lugares do passado ao descrevê-los, como a casa da infância, por exemplo. Mas esses espaços serão apenas orientados, não sendo possível dizê-lo de maneira objetiva; "o segredo nunca tem uma totalidade objetiva. Por esse caminho, orientamos o onirismo, não o concluímos", portanto tudo que é descrito, transmitido, é "orientado ao onirismo". (Bachelard, 2000 p. 206)

Entretanto, a atividade de analisar subjetividades é complexa, já que, como define Merleau Ponty (1993, p.27 - 28), o homem entende muito bem o que é ver, ouvir e sentir, mas ao transportar esses objetos para a consciência, comete-se comumente o que os psicólogos denominam "experience error", ou seja, "supomos de um só golpe em nossa consciência das coisas aquilo que sabemos estar nas coisas".

Esses elementos, segundo Ponty (1993), só podem ser percebidos por meio da percepção, e as sensações humanas possuem caráter objetivo. À ciência cabe analisa-las ao reconhecer seus conjuntos significativos.

Sabendo dos conceitos apresentados, é possível retornar à Bachelard (2000, p. 206) e compreender os "valores de intimidade": ao ler a descrição de um espaço, os valores de intimidade "são tão absorventes que o leitor não lê mais seu quarto: revê o quarto dele".is apresenta como ponto de partida a análise da relação de intimidade que é criada de maneira individual entre as pessoas e os espaços narrados.

A concepção do espaço físico isolado do ambiente é, para Mayumi (1989), uma característica exclusiva dos adultos. Para as crianças, os espaços são definidos de acordo com suas emoções: espaço-medo, espaço-alegria, espaçobrincar, espaço-curiosidade, etc. Uma riqueza que pode ser explorada para incentivar a capacidade criativa das crianças, e possibilitar-Ihes contribuir para a criação de uma cidade mais lúdica.

Nesse contexto, acredita-se que as relações entre arquitetura, educação e infância possam, a partir da mediação digital e da imersão em realidade virtual, fornecer mecanismos de criação de um imaginário de cidades e grupos mais inclusivos e cooperativos. Esperase que em um futuro próximo, cidadãos com maior consciência do espaço em que vivem possam trazer outras contribuições e visões de mundo para experiências cotidianas. 


\section{METODOLOGIA}

Para a implementação das ações de pesquisa que fornecem a base para este artigo, três contos literários foram selecionados, e em todos a importância da construção do lugar é elemento intrínseco à narrativa. Os contos selecionados são: País Nenhum (Shaun Tan), Casa Tomada (Julio Cortázar), e Metamorfose (Franz Kafka). Inicialmente foram realizadas as adaptações das narrativas, para serem apresentadas em sala de aula.

A seguir, foram realizadas as visitas, nas quais, após a contação das histórias, foi solicitado às crianças que representassem esses espaços por meio de desenhos livres. Na sequência, seguiu-se uma etapa de manipulação digital das imagens, para posterior apresentação por meio de óculos de realidade virtual e, por fim, outra visita foi realizada, para a experiência de imersão 3D, a partir dos desenhos produzidos pelos participantes.

\section{ESPACIALIZAR LUGARES NARRADOS}

Há, de acordo com Lucrécia Ferrara (2007), uma relação hierárquica em que quanto mais tempo permanece-se em um espaço, mais importante ele se torna. Contudo, ainda segundo a autora, os espaços não devem ser compreendidos como simples suportes das dinâmicas humanas, já que isso elimina a riqueza e potencialidade dos lugares, por vezes utópicos, construídos em outras mídias, com diferentes cores, luzes, imagens e sons.

A emergência do ciberespaço permitiu a mudança dos espaços como suportes, transformando-os em, segundo a autora, lugares de relações polisensíveis, ou seja, espacialidades. Nesse contexto, Ferrara (2007), defende que transportar espaços para espacialidades, dotando-os de múltiplos significados relacionados à vida cotidiana, evidenciando o abstrato e dando representação a coisas sem sentidos aparentes, possibilita a ligação entre elementos heterogêneos e oferecem à percepção uma nova esfera, rica em associações e cognições.

Na mesma linha, Mayumi (1989), defende que durante o processo de constituição e apropriação, os espaços físicos começam a adquirir outras condições, transformando-se em ambientes. Os ambientes são ricos em dinâmica, carregam as particularidades das pessoas e são, segundo a autora, ricos em componentes subjetivos.

Assim, os espaços têm o potencial de transpassar o lugar físico e criar em cada indivíduo um signo próprio, como define Pignatari (2004), ou uma poética própria, como define Bachelard (2000). E nesse sentido, pode-se explorar as relações entre o imaginário infantil e os potenciais para a transformação de espacialidades em espaços, de acordo com Ferrara (2007), ou ambientes, seguindo Mayumi (1989).

Na pesquisa, essa relação é explorada a partir dos contos literários. Dado ao dinamismo e à estrutura, em geral, mais facilmente adaptável para um vocabulário leve e infantil, sem perder o sentido principal da narrativa.

\section{EXPERIÊNCIAS}

Para Montaner (2017), a experiência não deve estar presa a aspectos do passado, mas comunicar-se com o presente, buscar compreender novas dinâmicas e, por fim, a inovação. Nesse sentido, o autor defende que, em um primeiro momento, a experiência é pessoal, mas deve ser transmitida de maneira interpessoal, transformando valores subjetivos em elementos objetivos, na tentativa de transmiti-los de maneira mais eficiente.

A tecnologia tem sido uma ferramenta com forte capacidade de transformar relações sociais, entretanto "há mais de dois séculos a rentabilidade capitalista tem imposto a tecnologia aplicada como medida de tudo" (Montaner, 2017, p. 92). E a alternativa é "resgatar e reinterpretar as tradições que entenderam a modernidade e a tecnologia como premissas de liberação e igualdade" (Montaner, 2017, p. 92).

Inversamente aos avanços tecnológicos e ao sentimento de autonomia gerado gradativamente, tais quais mobilidade, relações sociais, gestão, trabalho, etc., as pessoas tendem a se sentir mais e mais controladas e mecanizadas (Montaner, 2017). Assim, questões sobre como humanizar o uso da tecnologia podem servir de bases para experiências que busquem reconectar pessoas e espaços físicos.

A pesquisa surge do desejo de criar ambientes que possam transportar mesmo adultos ao mundo empírico e sensitivo da criança, tendo como intermédio a literatura. A tecnologia, em específico os óculos de realidade virtual, cria o intermédio para a imersão no contexto imaginário criado pelas crianças.

Nesse cenário, a organização de elementos simbólicos presentes nos textos possibilita evidenciar o suporte, transformando-o, mesmo que momentaneamente, a relação entre pessoas, tecnologia e espaços. Mas, para que isso seja possível, a montagem se torna o principal instrumento que "oferece sínteses cognitivas através de associações entre elementos díspares e heterogêneos para, com eles, construir espacialidades com qualidades estéticas e comunicantes" (Ferrara, 2007, p. 34).

Aqui, compreende-se montagem como a ferramenta que conecta as diferentes interpretações das histórias, materializadas por meio de desenhos livres criados pelas crianças, ao universo lúdico que surge em cada experiência com a união de diferentes leituras. Conexões que "isoladamente, podem nada significar, pois só se fazem notáveis se apreendidos na montagem que os organiza" (Ferrara, 2007, p. 35).

As experiências da pesquisa ocorrem, então, em três níveis: especulação das capacidades de transposição de elementos distintos, e muitas vezes subjetivos, a espacialidades simples e facilmente compreensíveis; de comunicação, seja pela adaptação de contos literários, ou pela interlocução com as crianças, igualmente de maneira leve, deixando-as livres para criarem ambientes que correspondam às interpretações criadas e, finalmente, a execução de montagens coerentes com as etapas anteriores, organizando elementos aparentemente díspares na tentativa de criar espacialidades.

\section{AÇÕES}

Durante os anos de 2017 e 2018, três ações foram realizadas e deram base para a execução deste artigo. Todas foram registradas em um blog que contém imagens 
a serem visualizadas em óculos de imersão 3D, disponibilizadas também em um aplicativo gratuito para Android e iOS, chamado Round.me, além de vídeos com as montagens e músicas produzidas a partir das vozes de reação das crianças ao verem seus desenhos em um contexto diferenciado.

As ações realizadas foram postas em prática em duas visitas: na primeira, os contos foram lidos e as crianças desenharam suas interpretações das histórias e, na segunda, de visualização nos óculos de imersão 3D. Para Santaella (2003), a realidade virtual se aproxima da arte por apresentar um potencial sensório, possibilitando um diálogo mais próximo com as espacialidades criadas.

Entre as visitas, ocorreram as manipulações digitais dos desenhos. Nesse momento buscou-se garantir a maior fidelidade possível. Por isso, os desenhos foram analisados separadamente e, após, divididos em categorias distintas (crianças que retrataram o exterior da casa descrita em determinada história, e as que retrataram o interior, por exemplo).

\section{PAÍS NENHUM}

O conto "País Nenhum", de Shaun Tan (2012), narra a história de uma família aparentemente sem grande poder aquisitivo ou crenças do que o mundo pode oferecer. Mas que ainda guarda pequenas tradições como fuga da realidade oferecida: uma delas é a decoração da árvore de natal, guardada no sótão, feita pelos filhos com papéis laminados de diferentes cores e formatos, ano após ano. Entretanto, naquele natal, o calor era tanto, que a árvore se colou ao teto e, na tentativa de salvá-la, um dos filhos caiu em um novo mundo, o pátio de dentro. Lá existia um jardim, um castelo e, ali, o calor não era tão grande. Logo, o lugar vira o segredo dos personagens da casa, que passam a fazer diversas atividades no local. No final da história, a família descobre que toda casa tem um pátio de dentro.

A primeira ação da pesquisa ocorreu no dia 24 de junho de 2017, com 13 (treze) crianças na escola de teatro Companhia das Artes, de Campo Grande- MS, e teve como base a narrativa anteriormente descrita. Esse foi um momento importante na definição dos procedimentos metodológicos que seriam aplicados nas próximas visitas, por ser uma primeira experiência com contato externo, dando lugar às imprevisibilidades e potenciais ainda não imaginados nas etapas de formulação teórica.

O momento que antecede o encontro teve grande importância na seleção da ordem dos contos a serem aplicados em todas as ações. Então, uma espécie de gradação foi selecionada: da narrativa mais leve, ou facilmente adaptável, à mais densa, Metamorfose, de Franz Kafka, acompanhando também o desenvolvimento e a possibilidade de prever certas respostas já vistas em etapas anteriores.

O primeiro conto, de três páginas e com vocabulário mais leve, não precisou de grandes ajustes para a execução da primeira visita. Por isso, a única preparação anterior foi de leitura, na tentativa de teatralizar a narrativa e, no momento da contação, captar ao máximo a atenção das crianças. Entretanto, mesmo que isso tenha sido realizado, percebeu-se já na ação descrita, uma alteração necessária: era preciso do auxílio de uma terceira pessoa para a contação de história nas próximas etapas, já que, para uma análise mais completa das experiências, era importante compreender a recepção das narrativas por parte das crianças.

Após a leitura, foi solicitado que desenhassem qualquer elemento presente na história e. durante aproximadamente uma hora, as treze crianças desenharam as mais diferentes interpretações. Todas se espalharam pela grande sala e desenharam livremente.

A etapa seguinte, de manipulação digital, durou três semanas. Em um primeiro momento os desenhos foram divididos em duas categorias, gerando duas montagens diferentes: a casa, de fora, e o mundo descoberto no "pátio de dentro". Posteriormente, a tentativa foi criar um universo lúdico, contudo uniforme, contendo todos os desenhos produzidos pelas crianças. Esperava-se que todas se sentissem incluídas no processo de composição da espacialidade gerada.

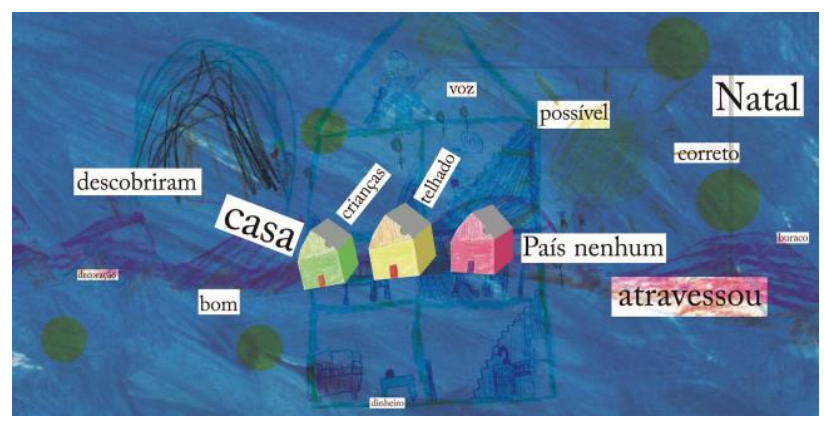

Figura 1: Composição utilizando-se dos desenhos das crianças retratando o exterior da casa, a partir do conto País Nenhum. Fonte: Autoria própria.

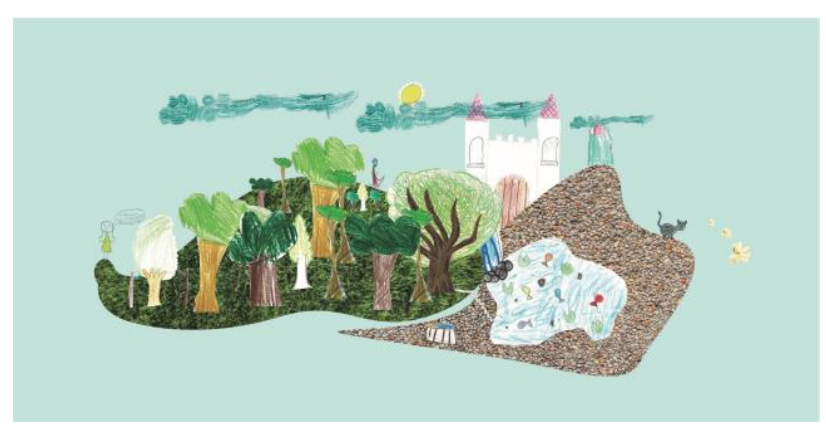

Figura 2: Composição utilizando-se dos desenhos das crianças retratando o pátio de dentro, a partir do conto País Nenhum. Fonte: Autoria própria.

No retorno, as montagens (figuras 1 e 2) foram mostradas às crianças nos óculos de realidade virtual. Entretanto, percebeu-se que três semanas era tempo suficiente para perder elementos importantes contidos na narrativa e, por isso, nas próximas ações seria necessário reduzir o intervalo entre a leitura e a visualização das montagens.

Para Montaner (2017, p. 77), “a apreensão da realidade por parte do sujeito ocorre através do que foi vivido, de sua história pessoal" e, nesse sentido, esperava-se que os desenhos, apesar de relacionados à narrativa, fossem particulares e facilmente identificáveis pelas crianças no momento de visualização das montagens, porém, desde a primeira ação foi possível notar que, quando em conjunto, 
poucos reconheciam suas criações, apesar de estarem presentes.

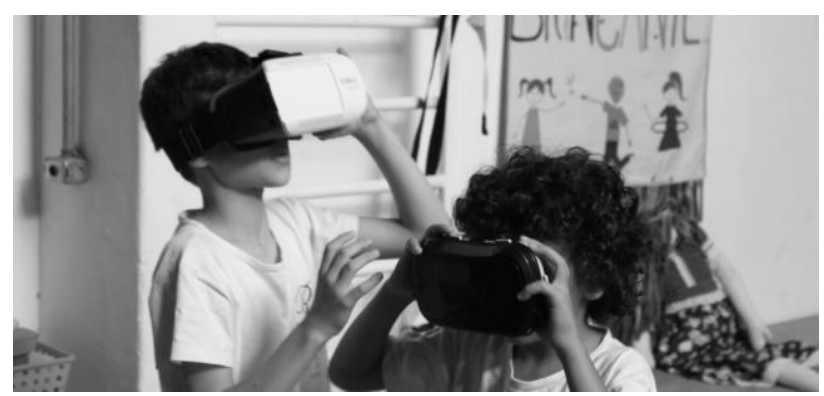

Figura 3: Crianças vendo as montagens produzidas a partir de seus desenhos. Fonte: Autoria própria.

À parte da necessidade das alterações previamente citadas, percebeu-se uma riqueza na pesquisa até então inexplorada. Mayumi (1989) defende que os espaços podem ser utilizados por meio de marcas pessoais (objetos, desenhos, nomes, etc), como ferramenta que proporciona um sentido de pertencimento. Indicando, nessa perspectiva, um potencial que a pesquisa possui de incentivar, por intermédio do ambiente virtual, espaços físicos mais colaborativos e inclusivos.

\section{CONTO DOIS: CASA TOMADA}

Em Casa Tomada, Julio Cortázar (2013) narra a história de dois irmãos que vivem em uma casa herdada da família, em que a construção do lugar é importante física e simbolicamente. Ambos vivem a mesma rotina, sempre em função de afazeres domésticos que lhes ocupam o dia todo e que não os permite uma vida social, já que nenhum personagem externo à casa é citado na narrativa. Pouco a pouco, o tranquilo espaço doméstico é transformado e os ambientes da residência começam a expulsar seus moradores que, no fim da história, fogem e jogam a chave na sarjeta.

No dia 29 de janeiro de 2018, ocorreu a segunda ação da pesquisa, baseada na narrativa de Cortázar (1946). Por apresentar uma descrição mais densa e longa, foi necessária uma adaptação da história e tradução para o francês, já que foi desenvolvida na cidade de Duclair, França. Para essa etapa, que teve a duração de uma semana, houve o auxílio de uma das professoras do colégio Gustave Flaubert, onde foi aplicada a experiência.

Por terem sido realizadas em um colégio, o tempo de duração das ações foi limitado a uma hora, por isso, tudo deveria ocorrer da maneira prevista. Na primeira visita, a leitura do texto adaptado e reduzido a três páginas foi realizada pela professora, em aproximadamente cinco minutos, no tempo restante, as crianças desenharam suas interpretações da história.

Durante a execução dos desenhos, era notável a diferença entre as representações, sobretudo das casas, feitas pelas crianças do Brasil e da França. O que vem ao encontro da definição de Bachelard (2000), em que os lugares de memória se cruzam com as interpretações dos espaços narrados, como uma espécie de reflexo do meio vivido, do tipo de composição arquitetônica, paisagística e urbanística observadas durante a vida.

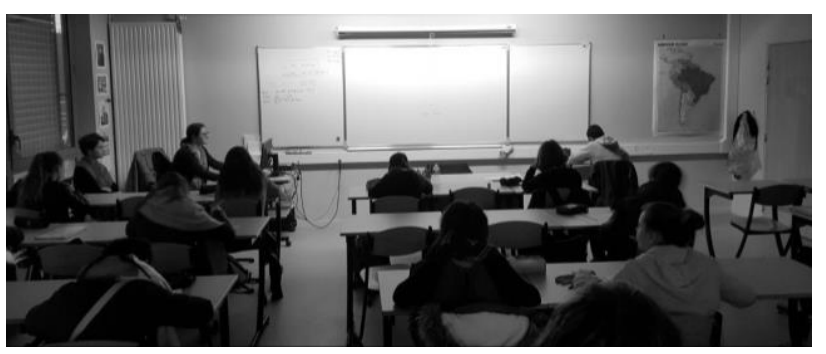

Figura 4: Execução dos desenhos em classe. Fonte: Autoria própria.

Nesse contexto, realizar a ação em outro país amplia o campo de discussão presente na pesquisa, ao possibilitar um paralelo entre diferentes percepções, colaborando na afirmativa de que os espaços físicos transpassam a pura construção e criam em cada indivíduo um símbolo no imaginário que é reflexo de signos subjetivos.

A etapa posterior, de manipulação digital dos desenhos, durou uma semana. Seguindo a lógica da ação anterior, os desenhos foram divididos entre representações do exterior e do interior da residência descrita na narrativa.

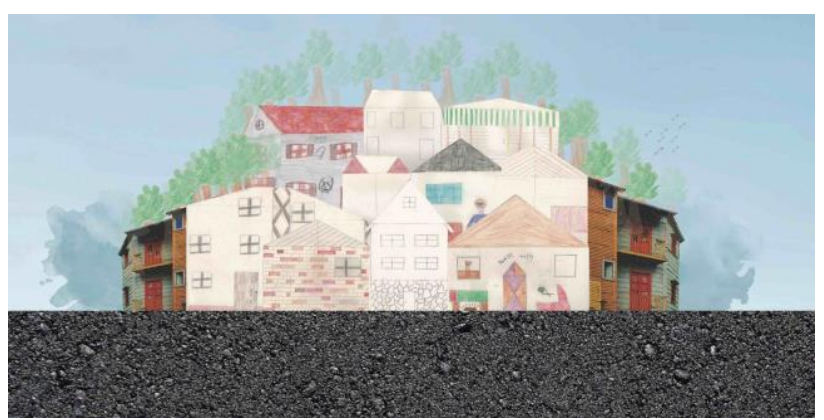

Figura 5: Composição utilizando-se dos desenhos das crianças retratando o exterior da casa, a partir do conto Casa Tomada. Fonte: Autoria própria.

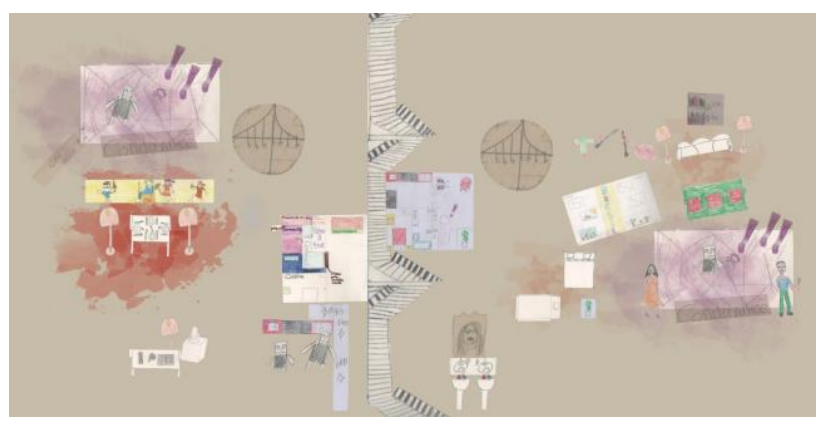

Figura 6: Composição utilizando-se dos desenhos das crianças retratando o interior da casa, a partir do conto Casa Tomada. Fonte: Autoria própria.

Para a exibição das montagens nos óculos de realidade virtual é necessário o aplicativo para celular e também rede de conexão à internet. No retorno da segunda ação, esse imperativo se fez um problema, atrasando a exibição das colagens para as crianças. Com vinte minutos de atraso no tempo previsto, as crianças começaram a ver seus desenhos "materializados" no contexto da história.

A diferença de representação dos ambientes em relação à primeira ação não foi determinante na percepção final da segunda experiência, ou seja, a recepção das crianças do 
espaço apenas imaginado anteriormente foi muito semelhante à etapa anterior. Dessa forma, é possível reafirmar o potencial da pesquisa de instigar a criatividade e o senso de colaboração e inclusão das crianças por meio do ambiente virtual.

\section{CONTO TRÊS: METAMORFOSE}

Em Metamorfose (2011), Franz Kafka narra o processo em que Gregor Samsa, personagem principal, se transforma em um inseto indefinido. No processo de adaptação com o novo corpo e com as novas perspectivas do ambiente doméstico, o autor descreve a mudança das relações entre o personagem e a sua família, trabalho, alimentação e seu próprio quarto.

O último conto, como citado anteriormente, possui uma narrativa mais densa e de difícil adaptação para o vocabulário infantil. Porém, é rica de detalhes e dá possibilidade de criação de espacialidades diversas, visto que alguns elementos, como as noções de perspectiva (se o inseto é grande ou pequeno em relação ao espaço físico em que vive) são vagos, possibilitando às crianças diferentes interpretações. Assim sendo, a etapa de adaptação da história teve grande importância para uma boa execução da última experiência da pesquisa.

A leitura do conto adaptado aconteceu no dia 5 de março de 2018, em na Escola Municipal Professora Iracema Maria Vicente, em Campo Grande -MS. Diferente das outras ações, que ocorreram com 13 (treze) e 18 (dezoito) crianças respectivamente, dessa vez eram 26 (vinte e seis). Contudo, esse fato não se apresentou como um problema. A contação de história, que se deu com o auxílio de uma colaboradora externa à pesquisa, e a execução dos desenhos ocorreram conforme previsto.

Com um intervalo de uma semana para o retorno, a etapa de manipulação digital das imagens seguiu a lógica das ações anteriores. Os desenhos foram divididos em duas categorias: a primeira delas é a metamorfose, ou o processo em que o personagem Gregor descobre que está se transformando em um inseto. Várias crianças se atentaram a esse momento, algumas transformaram 0 personagem em um herói, como o de histórias em quadrinhos, outras desenharam um personagem meio homem, meio animal. A segunda categoria, que gerou uma segunda montagem, foi baseada na representação da casa do personagem principal a partir da descrição de alguns elementos, como a proporção da cama, iluminação, o armário, um relógio, etc.

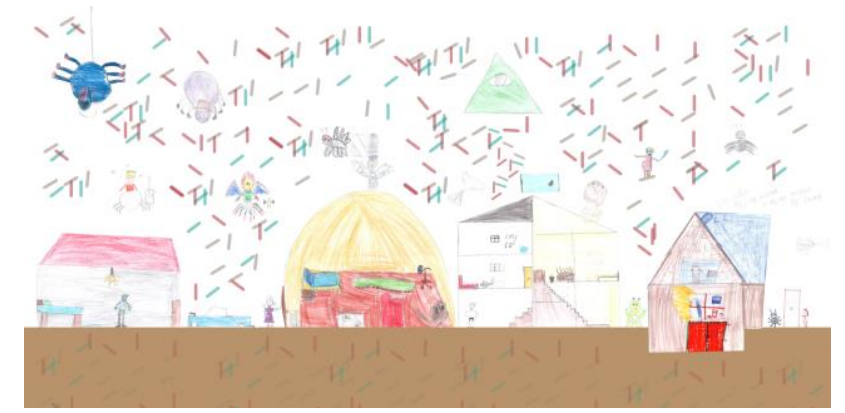

Figura 9: Composição utilizando-se dos desenhos das crianças retratando o exterior da casa, a partir do conto Metamorfose. Fonte: Autoria própria.

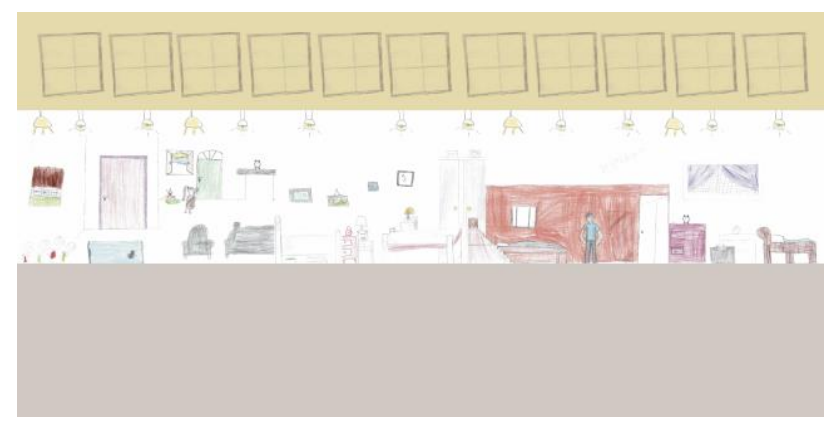

Figura 7: Composição utilizando-se dos desenhos das crianças retratando o interior casa, a partir do conto Metamorfose. Fonte: Autoria própria.

Segundo Mayumi (1989), as instituições de ensino representam um instrumento de poder e de intimidação sobre as crianças. Isso porque o espaço escolar, com mesas e cadeiras postas em posições pré-estabelecidas limitam os movimentos mais livre e impedem a sensação de pertencimento. Nessa última ação, notou-se que a rigidez de uma escola pode se apresentar como elemento limitador de ações que fogem do padrão: a professora pediu que as crianças permanecessem sentadas durante a visualização das imagens (figura 9), ação que, potencialmente, interferiu na percepção dos ambientes criados a partir dos desenhos.

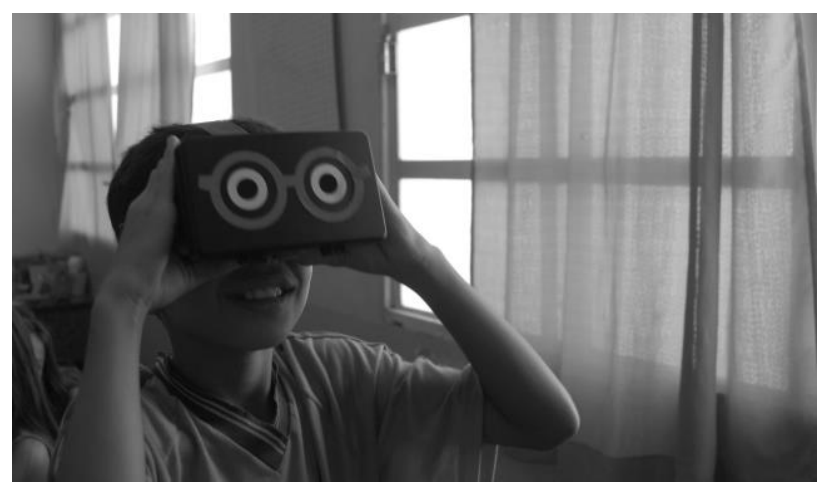

Figura 8: Criança visualizando as espacialidades criadas a partir do conto Metamorfose. Fonte: Eduardo Azevedo.

Contudo, o interesse que as crianças demonstraram pelos óculos de realidade virtual e também de descobrir as espacialidades criadas - e se conectarem com elas por meio de seus desenhos, contribuiu para que o objetivo principal da ação ainda fosse alcançado.

\section{CONSIDERAÇÕES FINAIS}

Durante o processo de realização das ações que deram base para este artigo, pouco a pouco, além das conclusões que foram sendo realizadas em cada etapa descrita, surgiram também expectativas para possíveis encaminhamentos. Nesse ínterim, as conclusões e sugestões acabam se misturando, já que a pesquisa se desenvolveu como "um recurso baseado em uma experimentação aberta e dirigida ao futuro" (Montaner, 2017, p. 77), ou seja, é viável aplica-la à tópicos variados e de maneiras diversas.

Ao desenharem os ambientes narrados em contos literários, as crianças demonstraram a capacidade de observação da realidade, além da visão crítica ilustrada a partir do imaginário produzido pelos contos. 
Independentemente dos textos narrarem sobretudo espaços internos, em muitos desenhos verificaram-se representações de cidades imaginadas, como um desdobramento dos modos de vida narrados, em uma relação desejável entre arquitetura e urbanismo.

Assim, percebeu-se que há uma projeção das vivências urbanas por parte das crianças ao criarem ambientes apenas descritos nas narrativas e imaginados individualmente. $\mathrm{E}$ isso pôde ser verificado, em um primeiro momento, por meio da transposição desses espaços narrados e imaginados para o papel, em forma de desenho e, em um segundo momento, para o ambiente virtual, já conectado com todas as interpretações, tornando-se coletivo.

Ao receber uma imagem manipulada por outro interpretante (no caso, os autores da pesquisa), algumas divergências puderam ser evidenciadas, afirmando a singularidade das interpretações de cada indivíduo. Admitindo esse fato, é possível torná-lo mais uma ferramenta que apta a instigar a curiosidade do observador, do que um potencial gerador de conflitos negativos.

Peirce (1995), apresenta a definição de semiose ilimitada, ou seja, a ideia de que cada elemento simbólico possibilita uma conexão sequencial entre signos. A semiose ilimitada parte de um signo gerando outros, em cadeia, de forma que a recepção de um mesmo elemento é sempre singular.

Nesse caso, mesmo que a montagem final de cada ação tenha sido produzida por um indivíduo exterior, a essência das interpretações individuais coexiste nas imagens. E, como nos ambientes físicos, determinados elementos podem vir a chamar mais atenção que outros, dependendo do observador que o analisa. E dessa forma, cada indivíduo que visualiza as imagens geradas pelas crianças a partir de narrativas específicas, pode ter diferentes percepções.

Outro elemento que pode influenciar na maneira com que os produtos gerados são percebidos é o suporte selecionado para a exibição. No caso, os óculos de realidade virtual possibilitam uma experiência de imersão individual, em que as trocas sobre o que foi vivenciado são mais imagéticas e subjetivas. Entretanto, existem outras possibilidades de interação com potenciais para serem exploradas, por exemplo, a projeção mapeada ou o uso de realidade aumentada que permitem experiências e percepções compartilhadas.
Pode-se, portanto, atribuir à pesquisa um aspecto urbanístico, tecnológico e político ao instigar a projeção das crianças em espaços urbanos desejáveis ou não, incluindo-as no processo de formação de ambientes mais flexíveis, horizontais e colaborativos. Trata-se de uma alternativa que possibilita a inserção das crianças em pautas políticas, amarrando a questão da educação a futuras possibilidades de políticas públicas.

Por fim, a pesquisa buscou conectar a materialidade e a brutalidade dos espaços físicos às realidades paralelas contidas em histórias imaginadas, a fim de contribuir para o enriquecimento das experiências cotidianas. Espera-se, com isso, que as crianças, como cidadãos do futuro, possam conectar-se com a tecnologia e com os espaços de maneira a transformar as cidades em lugares lúdicos, compartilhados e de pertencimento.

\section{AGRADECIMENTOS}

Agradecemos ao grupo de pesquisa Algo+Ritmo, à Univesidade Federal do Mato Grosso do Sul (UFMS), à escola de arte-educação Cia. das Artes, à Escola Municipal Professora Iracema Maria Vicente, ao Collège Gustave Flaubert e ao Comitê Científico Internacional do SIGraDi 2018 pela oportunidade de apresentar essa pesquisa.

\section{REFERÊNCIAS}

Bachelard, G. (2000). A poética do espaço. São Paulo, SP: Martins Fontes.

Cortázar, J. (2013) Casa Tomada. São Paulo, SP: Cosac Naify.

Ferrara, L. (2007). Espaços comunicantes. São Paulo, SP: Ananablume Editora.

Kafka, F. (2011). Metamorfose. São Paulo, SP: Penguin Companhia.

Lima, M. S. (1989), A cidade e a criança, São Paulo, SP: Nobel.

Merleau-Ponty, M. (1999). Fenomenologia da perceção, SP: Martins Fontes.

Montaner, J. M. (2017). Do diagram às experiências, rumo à uma arquitetura de ação. Barcelona: Editora Gustavo Gili, SL.

Peirce, C. S. (1995) Semiótica. São Paulo, SP: Annablume.

Pignatari, D. (2004). Semiótica da arte e da arquitetura. Cotia, SP: Ateliê Editorial.

Santaella, F. (2003). Culturas e artes do pós- humano. São Paulo, SP: Editora Paulus.

Tan, S. (2012). País nenhum. São Paulo, SP: Cosac Naify. 